\title{
Considering the dilemma of societal alignment: A response
}

\author{
Barbara Ribeiro $^{1 *}$, Philip Shapira ${ }^{1,2,3}$, Paul Benneworth ${ }^{4,5}$, \\ Lars Bengtsson $^{6}$, Susanne Bührer ${ }^{7}$, Elena Castro-Martínez ${ }^{8}$, \\ Meiken Hansen ${ }^{9,10}$, Katharina Jarmai ${ }^{11,12}$, Ralf Lindner ${ }^{7}$, \\ Julia Olmos-Peñuela ${ }^{13}$, and Cordula Ott ${ }^{14}$
}

June 2019

(Preface: July 2020)

(Posted on SocArXiv, 28 August 2020)

\begin{abstract}
The publication of our article "Introducing the dilemma of societal alignment for inclusive and responsible research and innovation" (Ribeiro et al., 2018) was accompanied by three commentaries (Guston, 2018; Nordmann, 2018; and Kuzma and Roberts, 2018). In the original article, we invoked Collingridge's dilemma of the social control of technology to introduce a complementary dilemma of "societal alignment" in the governance of science, technology and innovation. Thoughtful and challenging critiques were presented in the three commentaries. In this paper, as completed in June 2019, we respond to those critiques and, in so doing, seek to further clarify and extend our arguments.
\end{abstract}

Affiliations: ${ }^{1}$ Manchester Institute of Innovation Research, Alliance Manchester Business School, University of Manchester, United Kingdom; ${ }^{2}$ SYNBIOCHEM, Manchester Institute of Biotechnology, University of Manchester, Manchester, UK; ${ }^{3}$ School of Public Policy, Georgia Institute of Technology, United States; ${ }^{4}$ Center for Higher Education Policy Studies (CHEPS), University of Twente, The Netherlands; ${ }^{5}$ Agderforskning, Kristiansand, Norway; ${ }^{6}$ Division of Innovation Engineering, Design Sciences, Faculty of Engineering, Lund University, Sweden; ${ }^{7}$ Fraunhofer Institute for Systems and Innovation Research, Germany; ${ }^{8}$ INGENIO (CSIC-UPV), Universitat Politècnica de València, Spain; ${ }^{9}$ Danish Board of Technology Foundation, Denmark; ${ }^{10}$ Technology and Innovation Management, DTU Management Engineering, Technical University of Denmark, Denmark; ${ }^{11}$ Institute for Managing Sustainability, Vienna University of Economics and Business, Austria; ${ }^{12}$ Institute for Business Ethics and Sustainable Strategy, University of Applied Sciences for Management \& Communication, Vienna, Austria; ${ }^{13}$ Department of Management, University of Valencia, Spain; ${ }^{14}$ Centre for Development and Environment (CDE), University of Bern, Switzerland.

*Corresponding author (Barbara.Ribeiro@manchester.ac.uk)

Keywords: Collingridge; inclusive innovation; responsible research and innovation; societal alignment; governance of science; technology and innovation

Citation: Ribeiro, B., Shapira, P., Benneworth, P., Bengtsson, L., Bührer, S., CastroMartínez, E., Hansen, M., Jarmai, K., Lindner, R., Olmos-Peñuela, J., and Ott, C. Considering the dilemma of societal alignment: A response. SocArXiv, 28 Aug. 2020. http://doi.org/10.31235/osf.io/ayd6c 


\section{Preface (July 2020)}

In late 2018 and into 2019, we worked on a rejoinder to comments on our article on the "dilemma of societal alignment". We completed our "response to the responses" in June 2019. After receiving editorial feedback and suggestions towards the end of 2019 from the Journal of Responsible Innovation, some of us had started to work on further revisions to our response. We planned to revise and resubmit in early 2020. Due in part to disruptions caused by the Covid-19 pandemic, we were unable to continue in developing our revisions.

In May 2020, we were deeply shocked and saddened by the sudden passing of our dear friend, colleague and co-author, Paul Benneworth. Paul was involved in leading the revision of the response alongside Barbara Ribeiro and Philip Shapira. Paul contributed with critical ideas for making our argument stronger and was a lead thinker and writer for the rejoinder and consideration of subsequent modifications. Paul is deeply missed by all of us.

Wishing to share the ideas that we were all working on together, we now post the response in the form of the manuscript as originally written in June 2019. 


\section{Link to the original article}

Ribeiro B, Bengtsson L, Benneworth P, Bührer S, Castro-Martínez E, Hansen M, Jarmai K, Lindner R, Olmos-Peñuela J, Ott C, \& Shapira P (2018). Introducing the dilemma of societal alignment for inclusive and responsible research and innovation, Journal of Responsible Innovation, 5:3, 316-331, https://doi.org/10.1080/23299460.2018.1495033

\section{Links to commentaries}

Guston D H (2018). ... Damned if you don't, Journal of Responsible Innovation, 5:3, 347352, https://doi.org/10.1080/23299460.2018.1506208

Kuzma J, \& Roberts P (2018). Cataloguing the barriers facing RRI in innovation pathways: a response to the dilemma of societal alignment, Journal of Responsible Innovation, 5:3, 338-346, https://doi.org/10.1080/23299460.2018.1511329

Nordmann A, (2018). The mundane alternative to a demiurgical conceit. Comment on Ribeiro et al. 'Introducing the dilemma of societal alignment for inclusive and responsible research and innovation', Journal of Responsible Innovation, 5:3, 332337, https://doi.org/10.1080/23299460.2018.1511331 


\title{
Considering the dilemma of societal alignment: A response to Guston (2018), Nordmann (2018), and Kuzma and Roberts (2018)
}

\author{
Barbara Ribeiro, Philip Shapira, Paul Benneworth, \\ Lars Bengtsson, Susanne Bührer, Elena Castro-Martínez, \\ Meiken Hansen, Katharina Jarmai, Ralf Lindner, \\ Julia Olmos-Peñuela, and Cordula Ott
}

June 2019

It is stimulating to publish a think piece that immediately becomes embroiled in intense discussion by peers. That is what happened with our recent discussion paper "Introducing the dilemma of societal alignment for inclusive and responsible research and innovation" (Ribeiro et al., 2018). As a starting point, we evoked Collingridge's (1980) dilemma of social control and introduced a complementary dilemma of societal alignment. Collingridge's dilemma suggests that early in the development of a technology, it is more amenable to control, but information is lacking regarding its societal implications. Later in that process, when the technology is deployed and the societal implications are apparent, control is difficult and costly (Ibid., p. 19). We then raised a further dilemma, that of societal alignment in the governance of science, technology and innovation. We contended that designing emerging technologies to better match social needs was not by definition unachievable, but the question of whether this was possible depended not only on informed and timely assessment but on a reorientation and reshaping of governance processes.

Our paper triggered three responses. Demurring on our definition of dilemma, David Guston (2018) reaffirmed the robustness of the Collingridge dilemma whilst highlighting the importance of building capacities to encourage the societal alignment of technology. Alfred Nordmann (2018) argued that since Collingridge presents a "real dilemma," it is hubristic to suggest that it can be "solved", although he allowed for the possibility of shaping the arrangements between technology and society if pursued in experimental and tentative ways. Jennifer Kuzma and Pat Roberts (2018) saw societal alignment not so much as a dilemma but as an important part of responsible research and innovation, whilst advocating a lowering of 
expectations for responsible research and innovation and societal alignment due to multiple practical barriers.

We acknowledge the importance of definitions and the need to be nuanced in arguing from general propositions to the particularities of decision-making that influence the relationships between technology and society. Yet, we should not fail to move forward on the underlying challenges of responsible research and innovation simply because of differences regarding what does or does not constitute a dilemma. As we read these three published commentaries, it seems that there is more that unites than divides them. In the spirit of constructive response, we attempt both to address the comments raised and to discern common ground. All four articles mobilised a version of the dilemma of social control based upon their own respective close readings and interpretation of Collingridge's classic text. In part, our disagreements appear to arise not only from the real challenges of meaningful societal engagement in responsible research and innovation, but also because of differing interpretations of the "social control" of technology. We therefore begin by setting out our interpretation of what Collingridge was - and what he was not - trying to achieve in proposing his dilemma of social control.

We are reminded that Collingridge sought to confront the problems wrought by the introduction and deployment of technologies that promised societal benefits that nevertheless appeared elusive to realise in practice. Collingridge cites the example of the Green Revolution - a series of technology-driven efforts to increase agricultural productivity, especially in developing countries, in the 1950s and 1960s. For Collingridge, the Green Revolution was successful from a technical perspective, but a failure from a societal view. He compares the Green Revolution to the 1940s Manhattan Project and the 1960s lunar landing project. In contrast to those other examples, the Green Revolution explicitly had as one of its main objectives improving the nutrition and well-being of the poorest populations. In this societal aim, it failed. In Collingridge's words, the Green Revolution "undoubtedly succeeded in increasing the total output of food and of protein" (Collingridge 1980, p. 14). However, while all three projects were successful in achieving their technical goals, the benefits of the Green Revolution "tended to go to those with access to credit, additional land, machinery and extra labour, a group quite exclusive of the very poor" (Ibid., p. 14). Collingride held that "the Green Revolution is highly successful in the sense of its technical achievements, but a total failure because these vast efforts have all been in quite the wrong direction" (Ibid., p. 15). 
In his discussion, Collingridge (1980) did not articulate a fundamental critique of promissory narratives in science, technology and innovation. He assumed that those behind the Green Revolution were genuinely committed to helping the poor, and the obstacle they faced were an inability to comprehend the implications of technology deployment. As Collingridge (Ibid., p. 15) observed: “this is what has robbed the Revolution's efforts of success; the lack of understanding of how the technical products of the Revolution interact with the society using them" (Ibid., p. 15). Here, the context of invention was decoupled from the context of implementation, without recognition of the contemporaneous argument (Winner, 1980) that the design as well as the operationalization of technical systems was embedded in political systems. Although this is a problematic point in Collingridge's thesis, it is less important than his appreciation that science, technology and innovation can be instrumental in creating new societal problems often leaving them unable to act as mechanisms to solve societal challenges. Although Collingridge drew attention to the problem of the unequal distribution of benefits of new technologies, he settles for recognising their "unanticipated social consequences which are not welcome" (Ibid., p. 16) as part of the rationale for his dilemma of control.

The dilemma of the social control of technology, as put forward by Collingridge, relates more to oversight of that technology than to proactive steering. Collingridge assumes that "technology often performs in the way originally intended" (Ibid., p. 16) without then questioning how technology is designed in the first place. This understanding of technology as an apolitical entity frames the particular ways in which Collingridge constructs the dilemma of control. The foundation of his dilemma concerns the problem of prediction, a challenge that Collingridge explicitly dismisses in his strategy, claiming we cannot predict new technologies' societal consequences until they are subsequently embedded in society. A further foundation of his argument is that over time, lock-ins and path dependencies make it increasingly difficult and expensive to change the diffusion and embeddedness of new technologies in society. Collingridge does raise the importance of keeping new technologies as reversible and flexible as possible and try to avoid overdependence on single technologies: he proposes developing parallel technological options, of monitoring performance and error, and managing the ways in which technology is deployed. His ultimate aim is to retain "the ability to change a technology, even when it is fully developed and diffused, so that any unwanted social consequences it may prove to have can be eliminated or ameliorated" (Ibid., p. 20-21). 
Yet, notwithstanding his assumptions about intentionality in technological design, Collingridge's conceptual framework and his strategies for managing new technologies in society has more gradations than suggested by simply positioning the dilemma of social control as presenting only impossible choices. A critique based on semantical purity, i.e. what constitutes a true dilemma Guston (2018), is arguably incomplete in interpreting Collingridge nor is it helpful in addressing the contemporary challenges of governing technological change. Guston (Ibid., p. 348) states that a moral dilemma is typically framed as "a choice between undesirable alternatives" and deploys a definition of dilemma that presupposes a logical and irreconcilable conflict between two available options. Nordmann (1980), like Guston, posits the Collingridge dilemma of the social control of technology as a "real dilemma", i.e. as an irresolvable situation (Ibid., p. 333). He further objects to the framing of the dilemma of societal alignment as a dilemma, because to do so would be to describe something that by definition cannot be addressed.

Where there are different interpretations of a term, it is reasonable to expect that one definition is used in an explicit and internally consistent way. A dilemma can be many things, but that does not mean that all dilemmas must be a single thing: it is only reasonable to demand that one definition is used in an internally consistent way. In the dilemma of societal alignment, our interpretation of dilemma does comply with modern and popular usage - that is, of a difficult situation. We term it a 'dilemma' to signal that this is more than just a problem to be overcome; rather it is a complex issue of balancing and choosing between competing and potentially contradictory demands. Scientific creativity and societal control each have the power to restrict the other under particular circumstances, and it is the dynamic tensions in these relationships that we wish to foreground. While Collingridge did not challenge technology's promissory narratives, we do seek to confront the underlying sociopolitical drivers which lead to technological choices being made that have undesirable societal outcomes, and that are difficult to control. We do experiment in the context of the dilemma of social control - as put by Guston, we use the dilemma of social control "as a model for another dilemma" that captures these dynamics. Guston (ibid, p. 348) himself notes that the "DSC [dilemma of social control] is not the soundest of all logical dilemmas."

What we term the "dilemma of societal alignment" arises because responsible research and innovation introduces an enhanced tension into governance systems in the relationships between the processes of science and technology and societal alignment, which individual actors have difficulty in resolving in particular technology development contexts. 
However, a dilemma, we maintain, can be interpreted as an emergent dynamic challenge in coupling these scientific actors together to achieve mutually desirable goals. In this usage, we maintain that we are consistent with Collingridge and with ourselves. Rather than viewing it as rigidly irresolvable, Collingridge put forward the dilemma of technological control as a framing for practical action - seeking to break down the resistance of technologies to control through such means as retaining the flexibility to change later. We also want to highlight the fact that responsibility within scientific governance systems has an emergent characteristic. We aim to tackle "the difficulties in democratising science, technology and innovation, addressing divergent stakeholder perspectives, and ensuring a closer correspondence between their benefits and the needs of diverse publics" (Ribeiro et al., 2018, p. 318). We foreground flexibility, messiness and contestation in the construction of problems, challenges (and dilemmas). Similarly, using the term "shaping” within Collingridge's conceptualisation, something that Guston (2018) challenges, would not be a problem given that Collingridge's ideas about practice avoided simplistic and binary choices. Our framing of the dilemma of societal alignment does not mean asking if we would be damned (or not) for pursuing societal alignment (or not), as suggested by Guston. Rather, it would mean asking what kinds of values we should pursue when imagining and designing new technologies - whose values these correspond to and whether they are compatible or not.

In his commentary, Nordmann is also sceptical of there being a relationship between the dilemma of societal alignment and that of social control. To justify why we raise the dilemma of societal alignment as a complementary or corresponding dilemma, it is again helpful to go back to Collingridge's original thesis. It is clear that a misalignment sits at the heart of the dilemma of control, between the objectives of new technologies and those of society and between the benefits generated by new technologies and the needs of society. Yet two further points are important here. First, the dilemma of social control only works if we assume that the design of new technologies is not open for contestation, this stage representing the early stages of their embeddedness in society well before they reach the markets. Indeed, both the dilemma of social control and the strategy to address it are positioned after technologies have been designed and while they are in the processes of being diffused. The dilemma of societal alignment focuses on the expression and the definition of societal and technological objectives that guide technological designs.

Second, for Collingridge, the management and monitoring of the dilemma of social control is largely restricted to arenas of scientific and policy debate where experts and 
decision-makers operate. Collingridge concedes that decisions on technological options are value-laden and political and is not oblivious to the need for those monitoring a technology to do so "with a minimum of secrecy" and to be drawn from "a range of backgrounds." (Collingridge, p.147). Nonetheless, while open to an adversarial approach, he maintains a technocratic view as to who should be involved. Quoting earlier work from the Council for Science and Society, Collingridge highlights that "the control of advanced technical projects on behalf of society must depend on the same principle as does science", thereby reiterating his view on the responsibility of legitimate actors (i.e. experts and decision-makers) for criticising "corporate decisions and actions" (Ibid, p. 147) that guide technological change.

In contrast to Collingridge, the dilemma of societal alignment is fundamentally concerned with the democratisation of technological change and to building broader and more inclusive arrays of spaces and actors, beyond Collingridge's pool of experts and decision-makers. In this movement towards democratisation, a core issue is the question of what and whose values are prioritised. How can we be responsive to different - sometimes opposing - systems of reference (e.g. a paradigm of growth and shareholder return versus another of sustainable development and equity)? Today, we seek (although do not necessarily achieve) broader and more inclusive participation and influence in science and technology design and decision-making. This is one of the foundations of responsible research and innovation. In this respect, the dilemma of the social control of technology, as framed by Collingridge, begets (and hence is related to) the dilemma of societal alignment for inclusive and responsible research innovation. Indeed, this relationship was always there: what we have sought to do is to make explicit this relationship and to remind that the alignment of technology with society is and will be immensely challenging.

Notwithstanding our efforts to stress the complexities involved, Kuzma and Roberts (2018) take issue with our exposition of the dilemma of societal alignment. They suggest that we understate the challenges of promoting responsible research and innovation, especially in science, technology and innovation policy domains that are highly controversial in sociopolitical terms. Such domains, as in biotechnology, are likely to be contested in terms of the acceptance of responsible research and innovation, with tensions resulting from the divergence of priorities and values between scientists and publics. For Kuzma and Roberts (2018), disagreement "between those within and those outside of the scientific community" (ibid, p. 339) may thwart the possibility of a democratic shaping of science, technology and innovation. 
Yet, such strains resonate with the core idea of a dilemma of societal alignment. We do not suggest there will not be contestation, nor do we imply that simply recognising the existence of this dilemma will spontaneously resolve those tensions. Indeed, Kuzma and Roberts are very helpful in further elaborating the challenges that we only sketched out in our original paper. Based on their own work, they focus on innovation pathways and potential barriers for responsible research and innovation at specific stages of the innovation process, distributed across micro (individual), meso (institutional) and macro (socio-political and macroeconomic) levels.

However, while we concur with much of what Kuzma and Roberts write, we do not agree with everything. They explore questions of power, and the roles and responsibilities of different actors involved in innovation pathways, and in so doing appeal to a temporal and somewhat linear model of innovation. This would offer, according to Kuzma and Roberts (2018), promising avenues to investigate barriers to responsible research and innovation. In the case of their own research, this happens in the context of a project in the field of medical technologies. Here, the authors identify a "historic atmosphere of distrust among, public, regulators, innovators and stakeholders" fuelled by philosophical divergences between these actors (Kuzma and Roberts, p. 340). They go on to explain, in the case of early-stage research, how the scientific community is uncertain and suspicious of the value of responsible research and innovation for their own work, seeing it as a burdensome process. What they also reveal is the scientific phobia about the potential phobia of societal actors in certain fields of scientific development.

But, by not challenging these barriers and simply pointing them out and highlighting their resilience, Kuzma and Roberts (2018) reinforce what the field of science and technology studies has criticised for decades in relation to the perception of the scientific community regarding publics and their understanding of science. That is, how the scientific community has defended itself by using the argument of the public deficit model: "many technology researchers hold the view that their work is too complicated for the public to understand and therefore it is dangerous to give the public anything but a nominal role when it comes to deciding what technology is worthy of pursuit." (Kuzma and Roberts 2018, p. 341). Consequently, non-scientific perspectives are disregarded as being inferior to those of scientists. Concurrently, responsible research and innovation is seen as an obstacle for the translation of scientific research into marketable products. Transparency and openness become problems, according to the authors. At the regulation level, again, more fear, now 
from government - which despite showing greater acceptance of responsible research and innovation, is afraid of a potential backlash from industry

Kuzma and Roberts (2018) depict a rather hostile environment for advancing a critical agenda on the ethical and societal aspects of new technologies and on their democratisation. They infer that responsible research and innovation is perceived by the scientific community, innovators and industry as an unnecessary burden, a process that will delay things and will hinder scientific freedom and the very possibility of science to translate into potential benefits for society. But a model that pre-allocates these roles and positions certainly constrains the narrative and the potential of responsible research and innovation. While we recognise in our own transdisciplinary experience and work the points made by Kuzma and Roberts (2018), our concern is that the authors state the view of the scientific community (and other stakeholders) as if it was a uniform view. In our view, the landscape is more differentiated and interactive, with many individuals, organisations, and sponsors attempting to push forward and engage others in new approaches. Indeed, Guston (2018) highlights the example of the Center for Nanotechnology in Society, which has worked to "demonstrate how the capacities of engagement, anticipation, and integration and their ensembles can help societal alignment processes manage innovation responsibility” (Ibid., p. 350).

We also take issue with the suggestion that those who are labelled as "RRI scholars" should "lower their expectations for innovation systems" (Kuzma and Roberts, ibid, p. 344). This is a controversial call - should it really be up to us, activists for the democratisation of science, technology and innovation systems, to change, rather than the systems themselves? We do not eschew practical and novel ways to foster responsible research and innovation, including those along the lines detailed by Kuzma and Roberts (2018). However, such initiatives will likely have a better chance to gather traction if they are set in the context of broader visions of how science and innovation could work to better align and engage with societal needs and values. We here evoke Kitcher's (2001) notion of "well-ordered science" in which academics and users work together on scientific questions coordinated into coherent progress through shared activities that signal what is good knowledge and what is not.

Societal partners participate in the communities in which knowledge is created, verified and disseminated - and respond to signals transmitted and received as to which knowledge is good or not: social partners are endogenous to these communities. From this perspective, "responsibility" is not an external threat to scientific decision-making, but a norm that may take hold within these decision-making communities, influencing individual judgements of 
quality that may ultimately help coordinate the community towards delivering innovation with a higher societal use.

We do not see the dilemma of societal alignment as one that involves choosing an exogenous "authority" for scientific responsibility that peers over scientists' shoulders to test their projects against their societal benefits thereby imposing burdens on and barriers to scientific progress. Rather, the difficulty is in developing nuanced and internalised coordination based on agents shaping their knowledge creation in anticipation of societal alignment concerns. The dilemma of societal alignment from a micro-perspective is how to involve societal partners in ways that are endogenous to the knowledge community (that societal partners are able to exercise judgement and shape community development rather than simply being consulted).

In our original article (Ribeiro et al., 2018), we propose forward-looking scenario development in decentralised deliberative communities, and it is clearly challenging to involve citizens in these activities in an endogenous way. But that does not mean that it impossible, nor that it cannot be done constructively. If it is endogenous to the system then their involvement may also improve qualitatively the outcomes of the science undertaken. The dilemma remains that it is problematic to involve both scientists and citizens in these activities in a constructive way without one version of 'progress' (the technological or the societal) dominating. In this respect, we concur with Kuzma and Roberts (2018) on the necessity of confronting barriers and building partnerships without compromising on the fundamental elements of responsible research and innovation.

We again thank the commentators for their analyses and critiques of our initial contribution. This debate particularly highlights the enduring value of Collingridge's contribution and the challenges it posed. We differ from two of the commentators in our understanding of how Collingridge posed the dilemma of social control of technology; we maintain that we interpret this dilemma in ways that reflect a full reading of Collingridge, where opportunities for management and monitoring are possible, albeit not easily accomplished. We further explain the rationale for the dilemma of societal alignment, which is rooted both in addressing the limited participatory perspectives contained in Collingridge and in framing the difficulties inherent in the formulation of inclusive and responsible research and innovation. Most importantly, we believe that we all agree on the need for, and the opportunities to engage concepts and practices of responsible research and innovation to facilitate and motivate the societal alignment of technological development. The core 
challenge in the dilemma of societal alignment is in integrating societal actors in meaningful ways in scientific and technological knowledge communities and decision-making so as to influence progress without one side or another determining it. 


\section{References}

Guston, D.H. 2018. ... Damned if you don't. Journal of Responsible Innovation 5:3, 347352. DOI: $10.1080 / 23299460.2018 .1506208$

Kitcher, P. 2001. Science, Truth and Democracy. Oxford: Oxford University Press

Kuzma, J., and P. Roberts. 2018. Cataloguing the barriers facing RRI in innovation pathways: a response to the dilemma of societal alignment. Journal of Responsible Innovation 5:3, 338-346. DOI: 10.1080/23299460.2018.1511329

Nordmann, A. 2018. The mundane alternative to a demiurgical conceit. Comment on Ribeiro et al. 'Introducing the dilemma of societal alignment for inclusive and responsible research and innovation'. Journal of Responsible Innovation 5:3, 332-337. DOI: $10.1080 / 23299460.2018 .1511331$

Ribeiro B., L. Bengtsson, P. Benneworth, S. Bührer, E. Castro-Martínez, M. Hansen, K. Jarmai, R. Lindner, J. Olmos-Peñuela, C. Ott, and P. Shapira. 2018. Introducing the dilemma of societal alignment for inclusive and responsible research and innovation. Journal of Responsible Innovation 5(3): 316-331. DOI: $10.1080 / 23299460.2018 .1495033$

Winner, L. 1980. Do Artifacts Have Politics? Daedalus 109(1): 121-136. 